\title{
Pyoderma gangrenosum and autoimmune chronic active hepatitis in a 17-year-old female
}

\author{
JoAnNe M. LANGLey, MD, EVe A. Roberts, MD, FRCPC, MOSHe Ipp, MD, FRCPC, \\ RONALD M. LAXER, MD, CM, FRCPC, LIONEL BOXALL, FRCP (LOND), M. JAMES PHILlips, MD, FRCPC
}

\begin{abstract}
A 17-year-old girl presented with fever, icterus and painful small nodules on her face and a larger nodular lesion on the left shin. The patient had fatigue, intermittent jaundice and abdominal pain over the preceding three months. The nodular lesions ulcerated and had the typical clinical and histopathological appearance of pyoderma gangrenosum. Although there was no hepatosplenomegaly, serum aminotransferases and immunoglobulin $\mathrm{G}$ were elevated; antismooth muscle antibodies were detectable. Inflammatory bowel disease was not present. Autoimmune chronic active hepatitis and pyoderma gangrenosum are a rare association and this is the youngest patient in whom the association has been reported. Can J Gastroenterol 1988;2(4):137-9
\end{abstract}

Key Words: Autoimmune chronic active hepatitis, Autoimmune disease, Lupoid hepatitis, Pyoderma gangrenosum
Droderma gangrenosum is AN Ulcerative skin disease characterized by one or more painful nodules which break down to form progressively enlarging ulcers (1). The condition is rare in children (2). Pyoderma gangrenosum can occur alone or in association with sysbowel disease and lymphoproliferative and rheumatic disorders (1). The reported association of pyoderma gangrenosum with chronic active hepatitis is rare, described in only seven adults (3-8). The association of these two conditions in a 17-year-old girl is reported. temic diseases such as inflammatory

\section{CASE PRESENTATION}

A previously healthy 17-year-old caucasian female was admitted to hospital with a three month history of fatigue, intermittent jaundice with right upper quadrant pain and a one month history of painful mouth ulcers. Three days prior to admission the patient developed hard, mobile, tender 'pea-sized' lumps on her face and back and a painful red nodule on the left shin.

On admission to the Hospital for Sick Children in Toronto the patient appeared unwell. The patient was febrile $\left(38.6^{\circ} \mathrm{C}\right)$ and had scleral icterus. Aph-
Departments of Pediatrics and Pathology, The Hospital for Sick Children, Toronto, Ontario Correspondence and reprints: Dr Eve A. Roberts, Division of Gastroenterology, The Hospital for Sick Children, 555 University Avenue, Toronto, Ontario M5G 1X8. Telephone (416) 598-6131 Received for publication. August 22, 1988. Accepted September 19, 1988 thous ulcers were present on the buccal mucosa and tongue. Erythematous, painful, warm nodules 1 to $2 \mathrm{~cm}$ in diameter were present on the back, face and legs and a similar $4 \mathrm{~cm}$ lesion was present on the left shin (Figure 1). There was right upper quadrant tenderness but no hepatosplenomegaly.

Laboratory investigations revealed: hemoglobin $109 \mathrm{~g} / \mathrm{L}$ (10.9 g/dL); white cell count $13,300 \mathrm{~mm}^{3}$; and erythrocyte sedimentation rate $80 \mathrm{~mm} / \mathrm{h}$. The platelet count and coagulation studies were normal. Total serum bilirubin was 39 $\mu \mathrm{mol} / \mathrm{L}(2.3 \mathrm{mg} / \mathrm{dL})$ with direct bilirubin $15 \mu \mathrm{mol} / \mathrm{L}(0.9 \mathrm{mg} / \mathrm{dL})$; serum aspartate aminotransferase $336 \mathrm{iu} / \mathrm{L}$ (normal equal to or less than 36); serum alanine aminotransferase $444 \mathrm{iu} / \mathrm{L}$ (normal equal to or less than 40). Anti-HAV, HBsAg and anti-HBs were negative. Antismooth muscle and antimicrosomal antibodies were positive. Antinuclear and antiDNA antibodies and rheumatoid factor were all negative. Serum immunoglobulin $\mathrm{G}$ was $30.5 \mathrm{~g} / \mathrm{L}$ (normal 8 to $15 \mathrm{~g} / \mathrm{L}$ ), $\operatorname{IgA} 2.89 \mathrm{~g} / \mathrm{L}$ (normal 0.9 to $3.2 \mathrm{~g} / \mathrm{L}$ ) and $\operatorname{lgM} 3.39 \mathrm{~g} / \mathrm{L}$ (normal 0.45 to $1.5 \mathrm{~g} / \mathrm{L}$ ). Total serum protein measured $80 \mathrm{~g} / \mathrm{L}(8.0$ $\mathrm{g} / \mathrm{dL})$ and albumin was $29 \mathrm{~g} / \mathrm{L}(2.9 \mathrm{~g} / \mathrm{dL})$.

Over the next three days the patient developed persistent fever (equal to or 


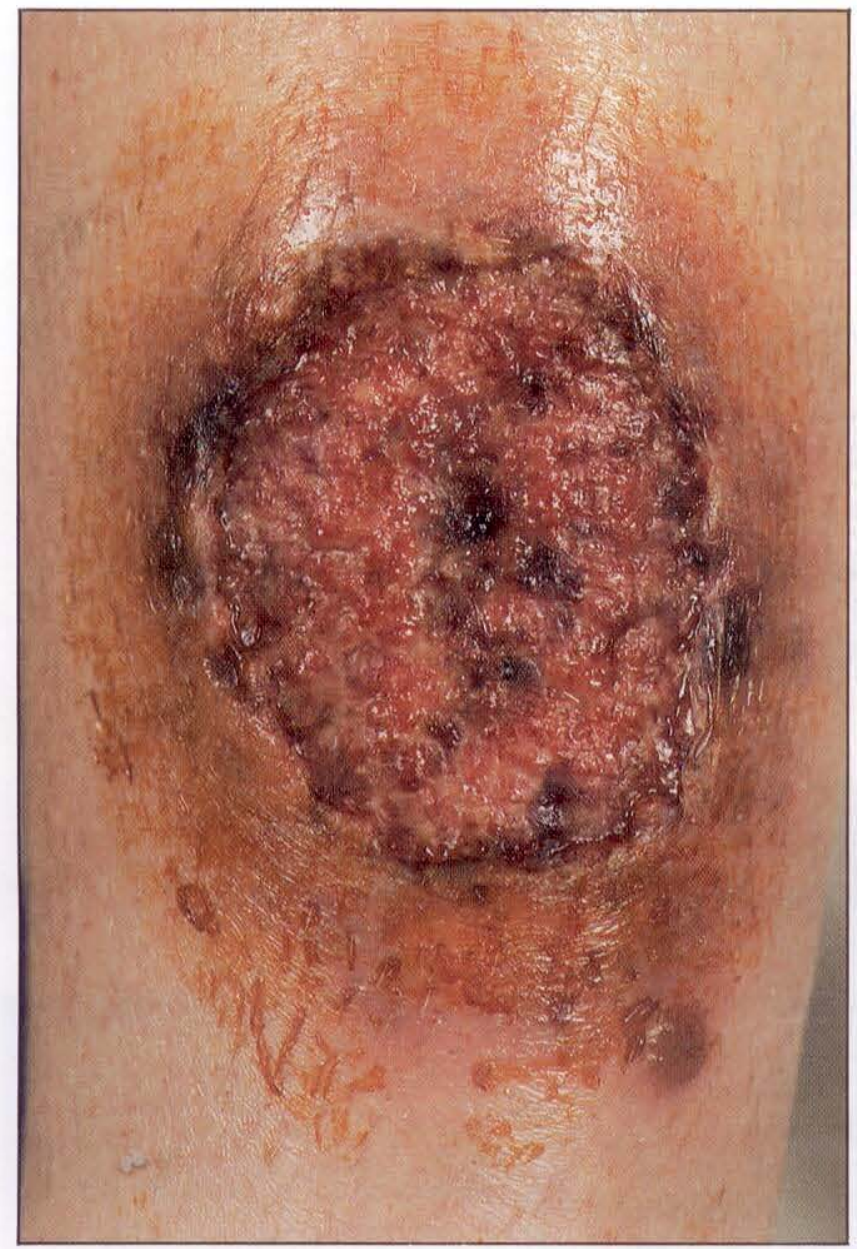

Figure 1) Pyoderma gangrenosum before treatment. Necrotic ulcer on the patient's left shin. The lesion had a mucopurulent base with a violaceous undermined border and was surrounded by a peripheral zone of erythema

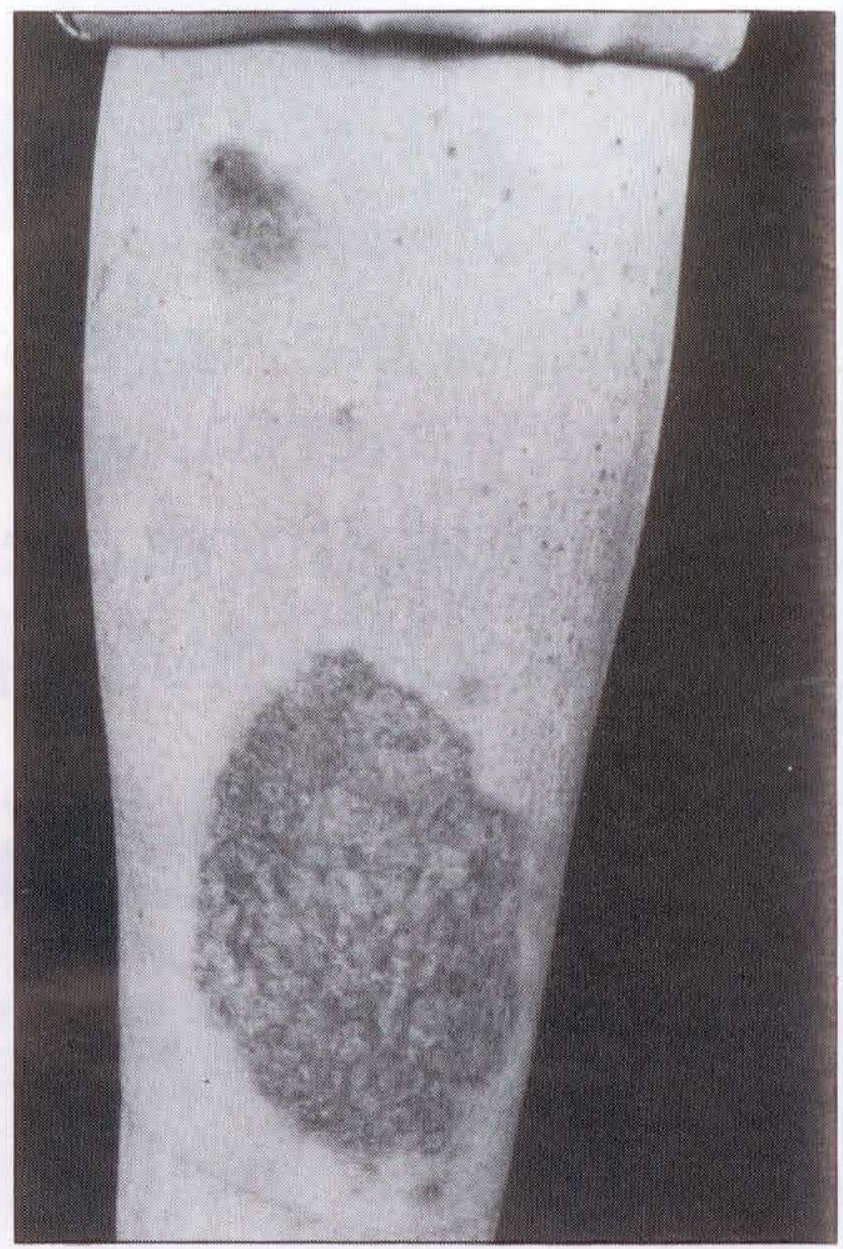

Figure 2) Resolving pyoderma gangrenosum. After six month' therapy with oral prednisone the left shin ulcer has epithelialized and is healing with skin formation greater than $40^{\circ} \mathrm{C}$ ) and migratory polyarthralgias. The lesions on the face and left leg showed necrotic ulceration with a mucopurulent base and a violaceous undermined border surrounded by a peripheral zone of erythema, typical of pyoderma gangrenosum. The patient developed tachypnea and a left pleural effusion. Multiple cultures of blood, throat, urine, stool, skin and the pleural effusion (transudate) were sterile. An echocardiogram showed no evidence of valvular vegetations. Abdominal ultrasound and sinus $\mathrm{x}$-rays were normal. A technetium methylene diphosphonate bone scan showed soft tissue uptake in the area of the leg ulcer but no evidence of osteomyelitis.

Skin and liver biopsies were obtained. A nonspecific acute inflammatory infiltrate was seen in the deep dermis, with negative immunofluorescence. This was consistent with pyoderma gangrenosum. The liver biopsy showed portal fibrosis and periportal septum formation, with little portal inflammatory infiltrate. An air contrast barium enema, upper gastrointestinal series and small bowel follow through were normal. Because an autoimmune etiology was suspected and no infectious agent found, the patient was treated with high dose corticosteroids. Methylprednisolone (1 g intravenously) was given daily for three days.

The patient defervesced on the second day of treatment and no new skin lesions appeared. The right upper quadrant pain and polyarthralgias resolved. After the three day course of methylprednisolone the patient was given $40 \mathrm{mg}$ oral prednisone daily. The aminotransferases returned to normal. As the patient was weaned off the prednisone to $20 \mathrm{mg}$ daily over the next month, the skin lesions flared. Subsequent improvement was achieved only after high dose prednisone (80 mg daily) was maintained. Ten months following presentation, steroid dose was slowly reduced. Initial skin lesions have healed with some scarring (Figure 2). Since then other equally severe skin lesions have developed. Her liver disease remains inactive.

\section{DISCUSSION}

In a review of pyoderma gangrenosum in childhood Powell and Perry (2) found only $4 \%$ of 180 patients seen at the Mayo Clinic between 1930 and 1982 had onset of disease before the age of 15 years and all had associated inflammatory bowel disease. Other disease entities commonly associated with pyoderma gangrenosum 
have included arthritis, hypogammaglobulinemia, pulmonary tuberculosis, leukemia and cardiovascular disease, with patients ranging in age from one month to 17 years. Although the association of pyoderma gangrenosum and autoimmune chronic active hepatitis has been reported previously, it is extremely uncommon. To the authors' knowledge, the patient described here is the youngest case of pyoderma gangrenosum with autoimmune chronic active hepatitis ever reported.

Chronic active hepatitis is a syndrome with various etiologies. Patients typically complain of hepatitic symptoms and have elevated serum aminotransferases. There is a variable histological picture of progressive liver cell destruction, including chronic inflammatory cell infiltrates in the portal areas, piecemeal necrosis and hepatocyte drop-out. In autoimmune chronic active hepatitis (also known as lupoid hepatitis), which was first described in young women, liver disease is associated with hypergammaglobulinemia, formation of autoantibodies and polyserositis. The present patient fulfills these criteria: the absence of portal inflammatory cell infiltrate on liver biopsy is likely attributable to ongoing steroid therapy at the time of biopsy. Other etiologies for chronic active hepatitis(hepatitis B infection, Wilson's disease, drug toxicity, alpha-1-antitrypsin deficiency) were excluded.

Corticosteroids are the treatment of choice for both pyoderma gangrenosum and autoimmune chronic active hepatitis (1.9). In the present patient, high dose prednisone treatment stopped the progression of existing ulceration, prevented the formation of new lesions and suppressed the liver disease. Cor ticosteroids alone and in various combinations with azathioprine, mercaptopurine, indomethacin and clofazimine have been used in the seven other patients with pyoderma gangrenosum and autoimmune chronic active hepatitis. Two of these patients died, one of hepatic failure after nine vears and the other of oppor tunistic infection $(3,4)$. In the rest of the patients, pyoderma gangrenosum was relatively well controlled although several had a relapsing course.

In the present patient, controlling the pyoderma gangrenosum has been more difficult than managing the autoimmune chronic active hepatitis. Potentially hepatotoxic agents such as the sulfones, which have been useful in the management of pyoderma gangrenosum in association with other conditions, are contraindicated in this case. Azathioprine might be a suitable additional drug in this patient because it has been used effectively in treating autoimmune chronic active hepatitis when combined with corticosteroids.

Although the initial treatment has been influenced primarily by the difficulty controlling pyoderma gangrenosum in the patient, the long term prognosis will be determined by the course of the liver disease. Progression to cirrhosis can occur despite resolution of symptoms and biochemical abnormalities. However, a recent retróspective analysis of 204 adult patients indicated that the presence of autoimmune markers and the absence of cirrhosis at diagnosis identifies patients who have a better prognosis (10). Although there has been no sign of inflammatory bowel disease, the possibility of it developing in the future cannot be excluded, particularly because pyoderma gangrenosum has been more commonly associated with inflammatory bowel disease than with autoimmune chronic active hepatitis in children.

The association of pyoderma gangrenosum and autoimmune chronic active hepatitis is rare in all age groups. However, when pyoderma gangrenosum is diagnosed, liver function should be assessed to determine whether autoimmune chronic active hepatitis is also present. Minimum investigations include measurement of serum aminotransfer- ases, total and conjugated bilirubin, IgG concentration and autoantibodies. Disordered immune function may be common to both pyoderma gangrenosum and autoimmune chronic active hepatitis, but the etiological basis for this association remains unclear.

\section{REFERENCES}

1. Wolff K, Stingl G. Pyoderma gangrenosum. In: Dermatology in General Medicine. New York:McGrawHill, 1987:1328-36.

2. Powell FC, Perry HD. Pyoderma gangrenosum in childhood. Arch Dermatol 1984; 120:757-61.

3. Byrne JPH, Hewitt M, Summerly R Pyoderma gangrenosum associated with active chronic hepatitis. Arch Dermatol 1976:112:1297-301.

4. Norris DA, Weston WL, Thorne G, et al. Pyoderma gangrenosum. Arch Dermatol 1978;114:906-11.

5. Burns DA, Sarkany I. Active chronic hepatitis and pyoderma gangrenosum: Report of a case. Clin Exp Dermatol 1979:4:465-9.

6. Marshall AW, Slonim JM, Smallwood RA, et al. The association of chronic active hepatitis with pyoderma gangrenosum. Aust NZ J Med 1978;8:656-8.

7. deCock KM, Thorne MG. The treatment of pyoderma gangrenosum with sodium cromoglycate. $\mathrm{Br}$ ] Dermatol 1980;102:231-3.

8. Sampson JA, Harris OD, Van Deth AG. Pyoderma gangrenosum and chronic active hepatitis: A case report. Aust ] Dermatol 1982;23:93-6.

9. Arasu TS, Wyllie K, Hatch TF, et al. Management of chronic aggressive hepatitis in children and adolescents. J Pediatr 1979;95:514-22.

10. Keating JJ, O'Brien CJ, Stellon AJ, et al. Influence of aetiology, clinical and histological features on survival in chronic active hepatitis: An analysis of 204 patients. Q] Med 1987;237:59-66.

\section{Phagégénisme géométrique et hépatite chronique auto-immune en évolution chez une patiente de 17 ans}

La malade est ágée de 17 ans et présente les symptômes suivants: fièvre, ictère, petits nodules douloureux au visage et lésion nodulaire plus grande sur le tibia droit. Au cours des trois mois précédant l'examen, elle a souffert de fatigue, de crises intermittentes de jaunisse et de douleurs abdominales. Les lésions nodulaires se sont ulcérées: elles ont l'apparence clinique typique et histopathologique des ulcères phagédéniques en terrier. Bien qu'il y ait absence d'hépato-splénomégalie, l'IgG et les amino-transférases sériques sont élevées; la présence d'anticorps anti-muscles lisses est décelée. Il n'y a aucune trace de maladie inflammatoire de l'intestin. L'hépatite chronique auto-immune en évolution e le phagédénisme géométrique sont rarement associés, et parmi les cas rappor tés à l'association, cette patiente est la plus jeune. 


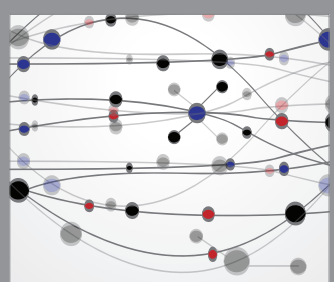

The Scientific World Journal
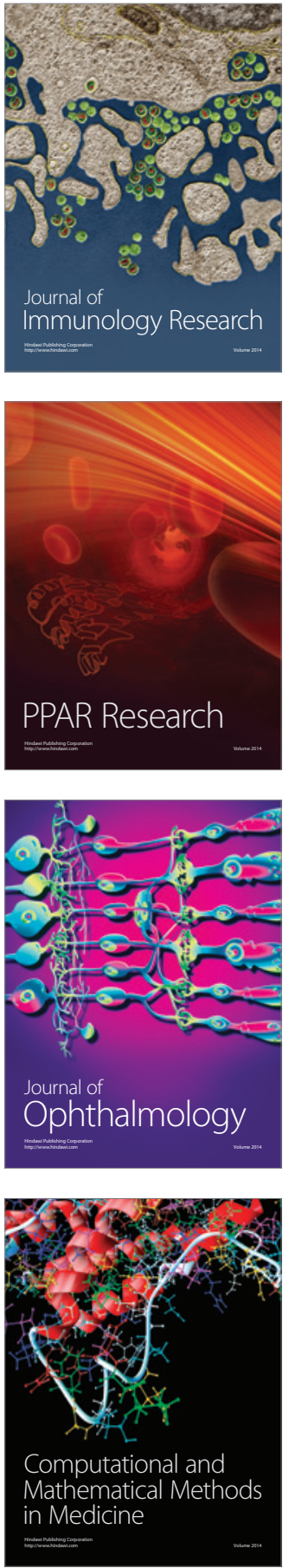

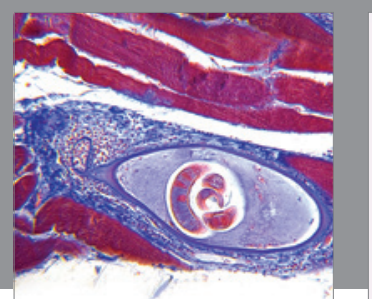

Gastroenterology Research and Practice

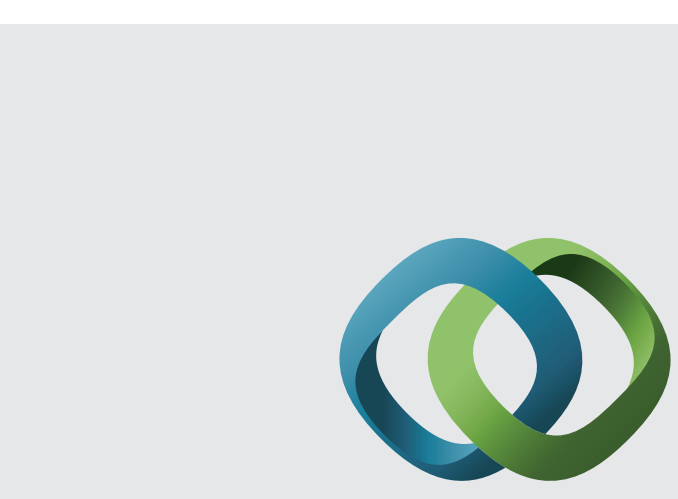

\section{Hindawi}

Submit your manuscripts at

http://www.hindawi.com
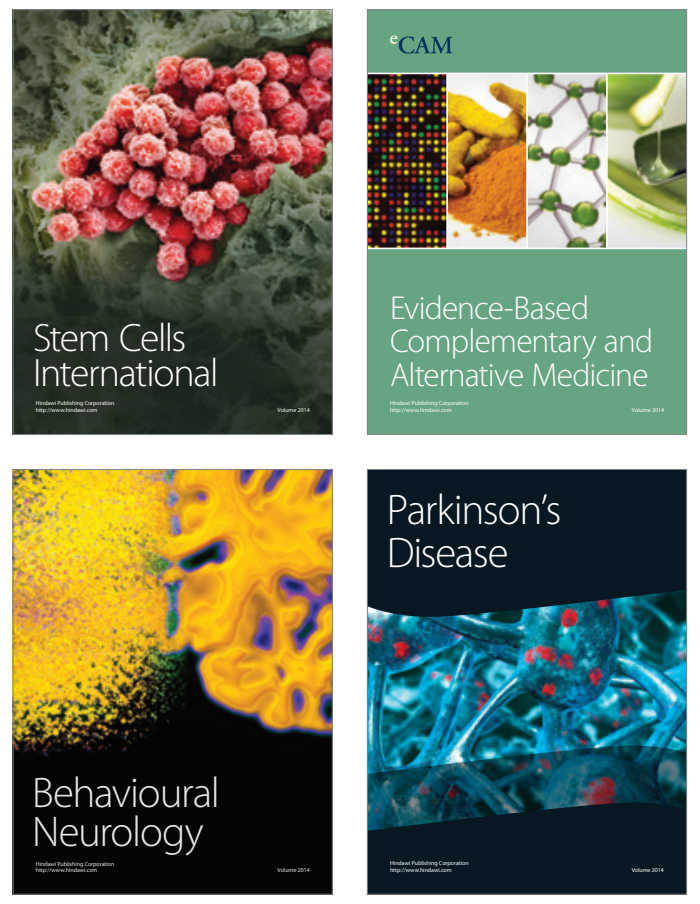
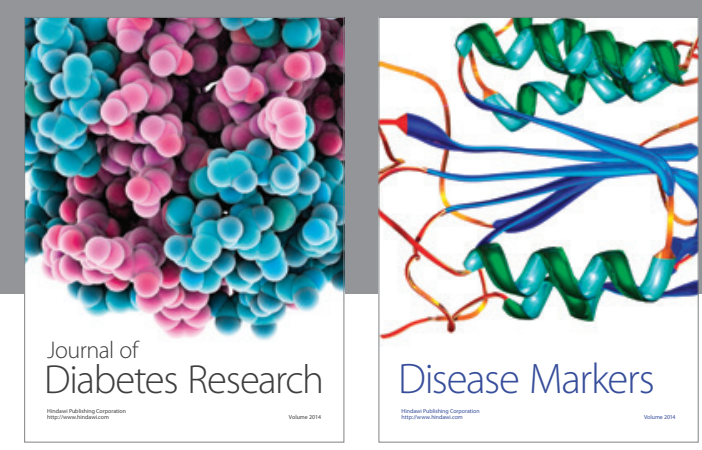

Disease Markers
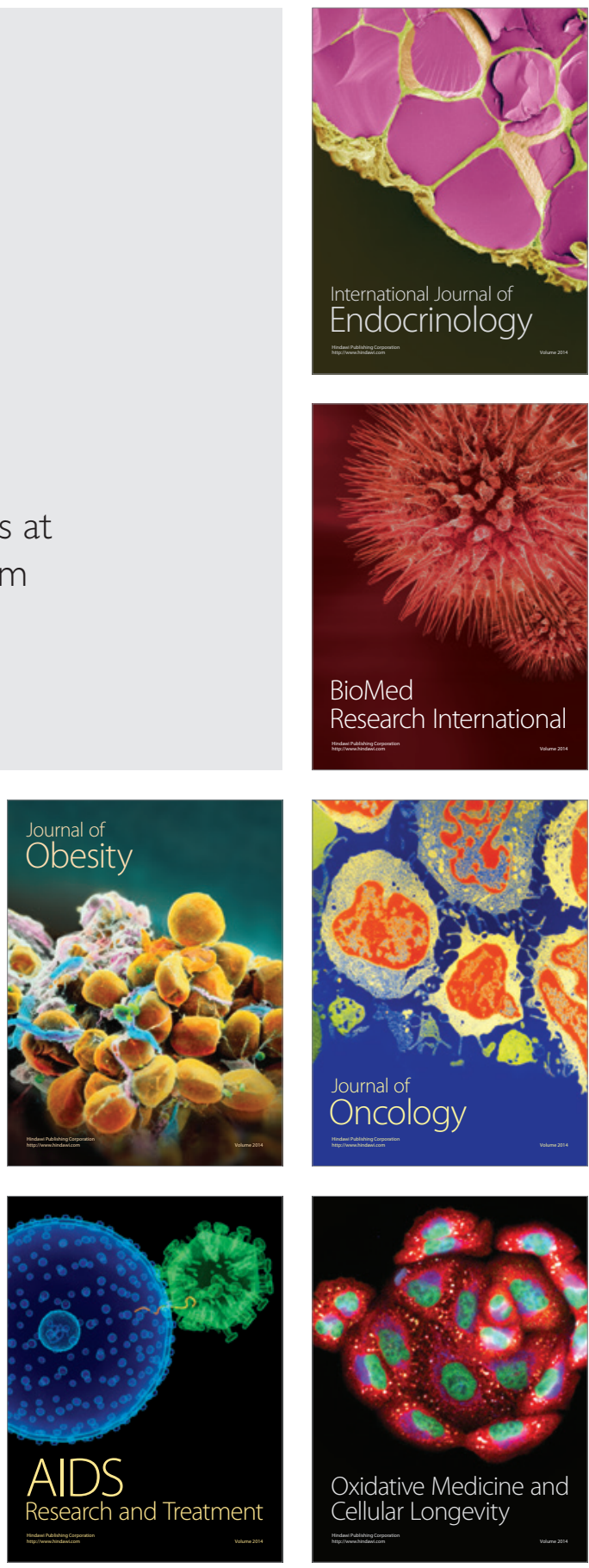